J5CER

I55N: 2708-1079

\title{
Impacts COVID-19 pandemic Diseases on Ethiopian Agriculture, Food Systems, Industries, and Mitigation and Adaptation Strategy
}

\begin{tabular}{|c|c|c|}
\hline & ${ }^{2}$ Rural Develop! & $\begin{array}{l}\text { Suleyman Abdureman Omer, Nuradin Abdi Hassen } \\
\text { esearch Facilities Management, Institution of Haramaya University, Ethiopia. } \\
\text { nent and Agricultural Extension Department, Institution of Haramaya University, Ethiopia. }\end{array}$ \\
\hline Received & 17 Sep 2020 & $\begin{array}{l}\text { Abstract- The COVID-19 pandemic is a recent outbreak in almost all parts of the world } \\
\text { including Ethiopia influencing the socio-economy of people and mainly threatening the } \\
\text { agriculture and food security of the least developed countries. The current desk review and } \\
\text { opinion synthesis by a multi-disciplinary team of experts from Haramaya University aimed at }\end{array}$ \\
\hline Revised & 04 Oct 2020 & assessing the probabl \\
\hline Accepted & 14 Oct 2020 & review of existing information were employed fo \\
\hline Published & 25 Oct 2020 & $\begin{array}{l}\text { due to the difficulty of data generation at this time of movement res } \\
\text { availability on websites of relevant institutions. Accordingly, the } \mathrm{i} \\
\text { synthesized and described following the major stages of food sup }\end{array}$ \\
\hline$\frac{\text { Correspond }}{\text { Suleyman }}$ & hor: & $\begin{array}{l}\text { handling and storage, processing and packaging, distribution and marketing, and consumption } \\
\text { are key messages drawn from the overall assessment }\end{array}$ \\
\hline $\begin{array}{l}\text { Email: } \\
\text { suleyman }\end{array}$ & In65@gmail.com & $\begin{array}{l}\text { Keywords: Adaptation, Agriculture, COVID-19, Food Systems, Impacts, Industries and Mitigation } \\
\text { Strategies }\end{array}$ \\
\hline pyri & 0: Suleyn & $\begin{array}{l}\text { Abdureman Omer, Nuradin Abdi Hassen. This is an open access dis } \\
\text { ded Access article distributed under the Creative Commons Attribution Licens } \\
\text { ch permits unrestricted use. }\end{array}$ \\
\hline $\begin{array}{l}\text { Citation } \\
\text { Agricult }\end{array}$ & $\begin{array}{l}\text { nan Abdur } \\
\text { d Systems, In }\end{array}$ & $\begin{array}{l}\text { an Omer, Nuradin Abdi Hassen. "Impacts COVID-19 pandemic Diseases on Ethiopian } \\
\text { tries, and Mitigation and Adaptation Strategy, "Journal of Science, Computing and Engineering }\end{array}$ \\
\hline
\end{tabular}

\section{INTRODUCTION}

The current novel coronavirus (COVID-19) outbreak was assumed to have originated from a seafood and wild food wet market in Wuhan and has quickly spread across China and to almost all countries in the world (WHO, 2020). Two-third of the world has imposed control of movement both within its borders and at international boundaries to contain the pandemic. Though these measures are necessary, they could adversely affect food and nutrition security through disruption of food supply chains. All past pandemics like Ebola, Severe Acute Respiratory Syndrome (SARS), and Middle East Respiratory Syndrome (MERS) had negative impacts on food and nutrition security particularly for vulnerable populations including internally displaced people, children, women, the elderly, persons with disabilities and the poor (Reperant and Osterhaus, 2017). As it stood now, the COVID-19 pandemic is already having a significant impact on supply chains and logistics, both for producers and consumers as evidenced by closed borders, national lockdowns, and the reduction in air traffic. This will have many adverse effects on food and nutrition security, particularly in developing countries like Ethiopia, where there are many vulnerable populations to food security. The first case of the pandemic was reported in Ethiopia on March 03, 2020, and to date, there are more than 100 reported cases almost in a month time. It is expected that the spread may increase until it reaches peak unless strong preventive measures are taken. Cognizant of this fact, the Ethiopian government has been taking several preventive measures including the state of emergency, partial to complete lockdown, quarantine, awareness creation and social protection to minimize the danger of the pandemic. Furthermore, resource mobilization from the community, private institutions and development organizations are going in an organized form. The government of Ethiopia has considered the probable effect of COVID-19 and to mitigate the effect and build resilience; the government announced a USD 154 million package to bolster health care and tax exemptions of imported products for the prevention and containment of COVID-19. The National Bank of Ethiopia (NBE) will avail 15 billion ETB liquidity in support of private banks, to allow them provide debt relief and refinancing to customers in need (World Bank, 2020b).

Such measures may continue depending on the intensity of the disease. However, there can be food security and agricultural risks emanating from the COVID-19 crisis unless clear directives and decisions for mitigations are outlined. Therefore, there is a need for careful planning in food supply considering the various actors along the food value chain and mainly on an inclusive basis, considering

Page 78 


\title{
Impacts COVID-19 pandemic Diseases on Ethiopian Agriculture, Food Systems, Industries, and Mitigation and Adaptation Strategy
}

\author{
Available at https://jscer.org
}

the vast, vulnerable groups of the nation to food insecurity. In connection with this, a team of researchers from Haramaya University, Ethiopia, compiled a brief synthesis of experts view on the impact of COVID-19 on Ethiopian food supply chains and its mitigation measures based on desk review from the experience of other countries and local observations, to inform the government, stakeholders and community possible ways of reducing COVID-19 related risks on agriculture and the food supply chains. The document contributes to the available information on the impact of COVID-19 on food supply chains and mitigation strategies for developing countries. It is a comprehensive document taking into account the possible effects on the major stages of food supply chains including, production, handling and storage, processing and packaging, distribution and marketing, and consumption with possible mitigation strategies for the impact at each stage. The document can help decision making by federal, regional, and local administrations and other stakeholders who are supporting the agriculture and food supply systems of the country. It, however, prioritizes the negative effects of the COVID-19; the potential positive effects are not covered in this document, except the spillovers from the mitigation strategies. Therefore, this paper is a rapid synthesis of experts' desk review and opinions on the probable impact of COVID-19 pandemics on Ethiopian agriculture along the food supply chains.

\section{A. Key impact assessment questions}

The following general and specific questions guide the synthesis on possible impact of COVID-19 on Agriculture, Food Systems, Industries and potential mitigation strategies

\section{a. General question}

What would be the possible effect of COVID-19 on agriculture, Industries and food supply chain in Ethiopia?

\section{b. Specific impact assessment questions}

1. What are the possible effects of COVID-19 on Agricultural the production of foods in Ethiopia? What are the alternative strategies for mitigating such effects?

2. What are the possible effects of COVID-19 on the handling, storage, processing and distribution of Agriculture, Industries and food in Ethiopia? What can be done to minimize the effects of COVID-19 on food loss?

3. What are the possible effects of COVID-19 on the marketing and consumption of Agriculture, Industries and food commodities in Ethiopia?

\section{MATERIALS AND METHODS}

\section{A. Data Sources, Data Collection and Analysis}

A multidisciplinary team of experts involving crop and livestock production experts, and socio-economic experts was established for conducting this rapid desk review and expert opinion assessment of the impact of COVID-19 on
Ethiopian agriculture and food security. The team shared specific tasks clustered by the thematic topics along the food supply chains. Brainstorming sessions were conducted among the experts to describe the key areas of probable COVID-19 impact and sort specific mitigation strategies. Relevant up-to-date documents were retrieved from blogs and relevant websites, to supplement the expert opinions.

The primary data sources are therefore mainly expert opinions and judgments, and that of secondary data were collected through review of materials published on lessons learned from previous pandemics as well as short notes and expert opinions published by different reputable sources such as International Food Policy Research Institute (IFPRI), Food and Agriculture Organization of the United Nations (FAO), International Livestock Research Institute (ILRI), World Bank (WB), United Nations Office for the Coordination of Humanitarian Affairs (OCHA), World Health Organization (WHO) and Ethiopian Economic Association (EEA). However, as the COVID-19 is a recent phenomenon and under investigation, very little literature directly dealing with its effects on agriculture is available. Therefore, to address the evidence gap, the experts team conducted several triangulation and cross-checking validations for ensuring the validity of the opinions.

Accordingly, the possible negative effect of COVID-19 and the adaptation/mitigation strategies were assessed at each food supply chain stages and food security dimensions simultaneously. The synthesis of findings follows a qualitative value chain approach where key concepts are thermalized under each food supply chain stage. Though the team believes that COVID-19 can have positive effects, focus was given to the probable negative effects and their mitigation strategies. However, some measures, if successful, indirectly imply the opportunities from the pandemic outbreak.

Team aimed at assessing the probable impact of the virus on the Ethiopian agriculture and food security and suggesting the possible mitigation and adaptation strategies to all responsible. The potential impacts of the pandemic and possible mitigations have been assessed considering the implications along the supply chains functions and stages, and each has been elaborated under the following topics: Production, Handling and storage, Processing and packaging, Distribution and marketing and, Consumption level. Experts' opinion and desk review of existing information were employed for the analysis and conclusions drawn, no statistical analyses were conducted using these data. The results are regarded as only indicative and were used only for synthesized narratively, subjective analysis and interpretation, due to the difficulty of data generation at this time of movement restriction and poor database availability on websites of relevant institutions.

III. RESULTS AND DISCUSSION

A. Impact of COVID-19 on Agricultural Production, Food Systems and Mitigation and Adaptation strategy 


\title{
Impacts COVID-19 pandemic Diseases on Ethiopian Agriculture, Food Systems, Industries, and Mitigation and Adaptation Strategy
}

\author{
Available at https://jscer.org
}

According to FAO (2020), food security analysis conducted in six regions of Ethiopia indicates that, an estimated 8 million people (27 percent of the 28.7 million people analyzed) were severely food insecure in Integrated Food Security Phase Classification (IPC) Phase 3 (Crisis) or worse between July and September 2019. Of these, about 6.1 million people were classified in IPC Phase 3 (Crisis) and about 1.9 million people in IPC Phase 4 (Emergency). The same report also indicated that between October 2019 and January 2020, Ethiopia's food security situation is likely to improve slightly due to the seasonal (Meher) harvests. Whereas, between February and June 2020, harvests from the Meher season will likely be dwindling and insufficient to sustain adequate food consumption through the lean season in areas that rely on Belg agricultural and pastoral production. Moreover, households relying on pastoral livelihoods typically depend on markets for food during this period. As food prices are expected to remain higher than previous years, these will most likely affect market access. About 8.5 million people are thus expected to be in Crisis (IPC Phase 3) or worse. Several factors exacerbate food insecurity in Ethiopia. Conflict and climatic factors have driven internal displacement in different parts of the country, disrupting livelihood activities and distorting food market systems and prices.

Ethiopia is highly food-insecure, with 54 percent of the population (52 million people) consuming less than 2,100 calories a day (Thome et al., 2016). According to the national official data about 26 percent of the rural people is already living below the national food poverty line (World Bank, 2020a). The annual inflation rate in Ethiopia climbed further to 22.6 percent in March of 2020 (26.9 percent came from food prices). If food prices increased because of supply shocks and constrained imports related to COVID-19, the food insecure population could rise. The above analysis of food security in Ethiopia was made before COVID-19 has become a global emergency and can be used as a baseline to combine the effects due to the pandemic for effective planning ahead. The prior food insecurity coupled with the current COVID-19 can immensely increase the vulnerable population in Ethiopia. The current pandemic has forced the government to implement restrictions of movements, divergence of the available resources more to health related materials like personal protective equipment (PPE), increased unemployment rate on the one hand and shortage of labor force, especially on labor intensive agricultural activities. Summaries stating potential short- and long-term effects of COVID -19 pandemic on production of agricultural products (assessed in terms of availability and access to inputs; energy/fuel availability and affordability; labor shortage and layoff; agricultural extension system, system; supporters/service providers: finance, cooperatives and unions, NGOs, grassroots community groups, research and development; local administration, desert locust control, restriction of pastoral movement etc.) and their respective adaptation and mitigation.

\section{a. Input supply and distributions (crop and livestock)}

Availability of agricultural inputs: Application of a range of agricultural packages and inputs including appropriate use of fertilizer and improved seeds, judicious use of pesticides and improved agronomic practices are required to increase agricultural production and productivity. In Ethiopia fertilizer and high yielding variety of crops are the most important technologies to increase crop production. Smallholder farmers rely on primary cooperatives, cooperative unions and, most significantly, informal markets to access agricultural inputs (HGT and LIFT, 2019). Fertilizers are often imported from Saudi Arabia, Morocco, China, Russia and Ukraine, and Agricultural Inputs Supply Enterprise (AISE), using operational service providers (transporters), transports fertilizers from Djibouti port to central warehouses, and through cooperative unions to farmers. Lockdowns due to the pandemic in input producing countries could affect timely delivery/transport of the inputs, which could in turn delay their supply to Djibouti port, and to end users within the country. Animal production is also largely affected by such inputs and services like feeds and healthcare. In Ethiopia, imbalances have already been witnessed between the available feed (in terms of quantity and quality) compared to what is required. According to FAO (2018), the difference between availability of feed resources as dry matter (DM), $\mathrm{ME}$ and $\mathrm{CP}$ and the requirements of all animal species (i.e. feed balance) showed that feed deficiency in Ethiopia is 9 percent as DM, while ME and CP deficiencies are 45 percent and 42 percent respectively, again suggesting lack of good quality feeds in the country.

Unprecedented COVID-19 pandemic has caused lockdowns/restriction of movements, closure of some input producing companies, and borders which has in turn reduced imports from countries such as China (Mahendra, 2020). Important inputs including fertilizers, improved seeds, feeds and pesticides are either not available or their prices are high due to shortages (FAO, 2020). Farmers will thus have lower incentives to produce crops and livestock, likely leading to lower yields and production in the near future. Long-term impact could lead to decline in agricultural production and productivity, increase in input price, and food insecurity may persist. Ensuring the availability of agricultural inputs to farmers at the right time of the season, with reasonable prices, and assuring incentives for production, should be a priority for the government in the next few months to avoid disruptions to input supply. Hence efficient transportation of agricultural inputs from one part of the country to another through creation of multiple channels for their timely delivery could be achieved by involving government bodies, cooperatives, unions and private sector. To this effect, lessons from Chinese 'Green channel' model (innovative initiative to help get inputs to farmers and produce to market) for import and distribution of agricultural inputs to keep the supply chains alive even during lockdown. For agricultural inputs imported from abroad, availability of inputs could be achieved through negotiations with

Page 80 


\title{
Impacts COVID-19 pandemic Diseases on Ethiopian Agriculture, Food Systems, Industries, and Mitigation and Adaptation Strategy
}

\author{
Available at https://jscer.org
}

producing countries. Furthermore, mobilizing local community so that resources and best practices are pulled together and used for food security could be helpful. To enable sustained good production of crops and livestock, smallholders need urgent support from government as well as private sector. Small poultry and dairy farmers in urban and peri-urban areas need more targeted help, as their pandemic-related input supply are urgent; while at the same time demand for livestock products has been affected due to closure and/or reduced demand of cafés and restaurants.

Government preparedness to fill the food scarcity gap through purchase and food aid is among short as well as long-term mitigation measures. It is also important that the country builds local capacity to produce agricultural inputs; example fertilizer demand could be met by completing construction of the local fertilizer blending plants, which is one of the goals to raising productivity and encouraging commercialization to reduce poverty and food insecurity (ATA, 2015). These fertilizer blending plants, if made operational, are expected to have capacity of over 250,000 tonnes per year. Flexible design of these plants allows them to accommodate a variety of new formulas, so, availability of fertilizer will be on board for crop production in the country. With regards to livestock production, majority of the feed processing plants are located in and around Addis Ababa while farmers in other urban and peri-urban areas face supply shortage or higher cost of transportation. Hence, incentivizing private agribusiness sectors like feed mills at different parts of the country will be essential as a long-term strategy since potential animals for commercial supply are found far from Addis Ababa.

Access to agricultural inputs: Movement restrictions imposed following the COVID-19 pandemic has resulted in sluggish supply due to longer collection and transportation time, higher loading and unloading markup, higher distribution cost and longer retail filling. Slowdowns could also impact the availability and movement of fertilizer, fuel and other inputs. This in turn results in decline in agricultural production and productivity, increase in input price, and food insecurity may persist. Therefore, the government needs to develop policies in the long-term to respond to these varied impacts to avoid the supply chain disruptions, higher input prices etc. Other possible areas of mitigation include subsidy for access to inputs, increasing access points, credit facilities (loan finance) for recovery from adverse effect of the pandemic, and encourage saving and investment by farmers. Energy (fuel) availability and affordability: In recent years, power-driven farm activities such as pump-driven irrigation, tractor-based land preparation, combine harvester/thresher, feed and milk processing, etc. are growing in the country. These all farm activities require dependable power source accessible when needed. Movement restrictions due to the pandemic could cause fuel scarcity and price hike, which in turn affects crop and livestock production. Possible mitigation areas to alleviate these challenges include establishing fuel reserve for farm implements and establishing sustainable energy supply system for agriculture sector, among others. Mechanized farming could be attractive to involve youth in food and feed production. In the long run we suggest the launching of environmentally friendly solar energy supply for small scale irrigation pumping.

\section{b. Labor shortage/layoff}

One of the short-term effects of COVID-19 is shortage of labor due to restriction of movement to contain the pandemic. Measures affecting the free movement of people, such as seasonal workers, might have an impact on food production. Agriculture labor force shortage in fear of the disease and because of illness could significantly affect the production of crops and livestock in Ethiopia. Such restriction of movement impedes many laborers not to move to their places of work or carry out their jobs. For instance, in the Central Rift Valley of Ethiopia, where most vegetable production occurs, labor is becoming scarce (Tamiru et al., 2020). Vegetable production is labor intensive and usually attracts a large number of daily laborers. In response to the restriction on travel and gatherings, these workers are increasingly returning to their villages. Reverse migration of labor from towns to villages as well as from schools to families in fear of the pandemic may add workforce to family labor although the risk of COVID-19 spread and competition for family food become high. On the other hand, there is labor layoff under floriculture industry due to marketing problem. Export of floriculture products (cut flowers, herbs, bedding plants etc.) has dropped by 70 percent due to lockdowns in consumer countries. The volume of flower export has dropped following the outbreak of COVID-19 pandemic. Consequently, in Ethiopia's flower industry a total of 150,000 employees are on the edge of losing their jobs (labor layoff) (Addis fortune, 2020).

In the long-run, COVID-19 could result in area and production reduction especially of labor-intensive agriculture, such as flowers and vegetables production. The reverse migration due to COVID-19 could also increase unemployment in rural areas. Moreover, in the long-term, foreign currency the country generates from export of horticultural crops could be reduced. The pandemic also increases inefficiency of commercial farms as a result of which some of them might even be closed. The short-term solution for enhancing the availability of labor could be facilitating careful movement of temporary or seasonal farm workers to areas where labor-intensive production (example vegetable production) are practiced. For reducing the risk of COVID-19 spread, self-quarantine of the returnee and establishing emergency shelter should be implemented in each location/region. Encouraging the returnees to engage in farming activities and minimizing reverse migration by stimulating agribusiness firms to operate safely (by applying COVID-19 prevention measures) should be taken as shortterm solution to minimize unemployment. The government could also subsidize the commercial farms and encourage them to pay wages to workers to avoid labor layoff. Availing labor-saving farm tools/machines suited to

Page 81 


\title{
Impacts COVID-19 pandemic Diseases on Ethiopian Agriculture, Food Systems, Industries, and Mitigation and Adaptation Strategy
}

\author{
Available at https://jscer.org
}

smallholder farmers and promotion of contract farming using irrigation to boost production could be practiced as a long-term solution for the available labor to avoid such unexpected risks. Promotion of bi/multilateral negotiations and versatility in production (i.e. possibility of growing alternative crops) needs to be encouraged in the future to avoid labor layoff from commercial farms in Ethiopia.

\section{c. Psychological effect}

COVID-19 pandemic is not just a medical phenomenon; it affects individuals and society in many ways, causing disruptions and mental stress. Panic and stress have also been linked to such outbreaks. Similarly, can be fear of isolation and quarantine and sometimes miscommunications about the type of food to consume. For example, demand for raw consumed foods such as meat, vegetables and fruits may decrease in fear of the virus and disrupt the demand and supply relationship by creating risk attitude and uncertainty about the future and loss of confidence by growers about what type and amount of agricultural crops to produce. In order to avoid such problems, it is necessary to provide psychological therapeutic measures and create optimistic mindset through counseling and provision of evidence-based information so that the society gets accurate information about the different foods and their relationship with COVID-19.

\section{d. Disruption of the agricultural extension system}

Ethiopia's extension system has great potential to help farmers throughout the country, with approximately 21 development agents (DAs) per 10,000 farmers, it is considered as one of the countries with strong public extension systems among Sub-Saharan African (SSA) countries in terms of human capital. As a result, the agriculture sector is an engine of growth in the country.

The COVID-19 could have short and long-run impacts on Ethiopian agriculture in general and extension systems in particular, thereby affecting the food security. The probable short-run impacts of the COVID-19 on the Ethiopian extension system could be the disruption of the normal and major activities of the extension services (advice, training, input delivery etc.) due to restrictions on movement, gathering, and meetings. Ban on movement restricts extension personnel from providing training at Farmers Training Centers (FTCs), demonstrations, field days, and visits to groups of farmers in contrast to what has been happening in the past. The other possible impact of COVID 19 on Ethiopian agricultural extension is related to prohibitions of market gatherings that disconnect farmers from the cash economy. These further limit the farmers' purchasing power of farm inputs and the adoption of farm technologies. A customized extension approach should be devised to mitigate the short-run disturbances on the extension functions related to COVID-19 and provide farmers with necessary information and inputs. To customize the extension service to COVID-19, the individual and mass extension methods should be adopted. Individual based extension method: Individual extension methods are time and labor-consuming but can be used for family extension approaches for communicating the household head on one to one basis for providing extension messages and advice. Alternatively, potential individuals and model farmers in each village can be contacted by the extension personnel. Then the model farmers can do the farmer-to-farmer extension in a protected manner from the pandemic. For instance, farmers with landholding of more than one hectare or who own livestock could be given priority services during the individual family extension services. Also, for extension workers, to reach a wider population, primary education teachers can be deployed with adequate training for dissemination of extension messages provided that they are adequately trained. The mass media or ICT based communication will help in efficient communication of large number of farmers at the same time and is cost-effective. For this purpose, mobile applications (e.g. mobile SMS messages), and local radios such as FM radios can be used to provide extension messages in local languages. The timing of extension broadcasting through radio needs to be conducive for farmers (e.g. evening is preferred to morning). For those farmers who are able to read and write, printed media and extension leaflets can be developed and distributed in local languages. The extension agent can provide technological packages, training, and advisory services to the targeted farmers in a protective manner from COVID-19. To be successful, the extension agents have to be oriented and trained and provided with Personal Protective Equipment (PPE) such as masks and gloves to protect themselves and farmers from the virus. In this regard, a new collaboration framework between health extension workers (HEWs) and development agents (DAs) has to be established.

In the long-run (after six months) in the worst case, there could be lower crop/livestock production and productivity and farmers may also be indebted and fail to repay input loans. For farmers and producer cooperatives, during such a big crisis time, a waiver policy for inputs purchased and long-term credit supply or in-kind contractual arrangements has to be prioritized. Besides, a tax waiver for agricultural inputs (seeds, feed, fertilizer, pesticides) import will stabilize price of farm inputs, as well as for waiving debts and loans associated with agricultural inputs.

In the long-run, the Ethiopian government can improve the agricultural extension system by (i) developing more innovative ICT based communication channels (e.g., mobile-based agricultural information delivery), (ii) rural radio-based extension training, and (iii) geographical information systems (GIS) for planning and monitoring extension activities. The application of GIS for agriculture extension would help the planning and forecasting of agricultural activities. (iv) initiating private extension systems. In many African countries such as Kenya and South Africa, private extension service providers have played a significant role in improving the agriculture sector. Diversification and involvement of the private sector in 


\title{
Impacts COVID-19 pandemic Diseases on Ethiopian Agriculture, Food Systems, Industries, and Mitigation and Adaptation Strategy
}

\author{
Available at https://jscer.org
}

extension service delivery will create employment opportunities for agricultural graduates and provide innovative services to farmers.

\section{e. Supporters/service providers}

Support sectors like finance, cooperatives and unions, NGOs, community organizations and research institutes are few, among others, having a greater role in affecting agricultural production and productivity.

Financial institutions: Financial institutions can affect economic growth through a growth in economic sector developments by efficiently carrying out its functions, among which is the provision of credit. Rural finance access (credit) plays a major role in the transformation of traditional agriculture into a modern/ commercial type, which enhances agricultural development. It is necessary for purchasing inputs needed for effective adoption of modern agricultural techniques. The main financial institutions that give financial services in Ethiopia are banks, insurance companies, microfinance institutions, cooperatives and informal financial institutions. The financial service offerings to agricultural sector in Ethiopia face gaps in terms of access to financial services and demand for financial services (Wegayehu and Mmatlou, 2017).

Financial institutions may be weakened due to COVID19 pandemic and may be unable to lend money to the farmers. Resources may be diverted to support prevention of COVID-19 efforts, affecting budgets for agricultural production. In the absence of credit, farmers could experience financial shortage to purchase agricultural inputs and services on time, which in turn could lead to lowered production. It is also expected that the prices of inputs be hiked due to movement restriction and farmers may need better financial services and government incentives. Strengthening financial access to small and medium scale farmers will enhance their capacity to increase production per unit time and space, and also improve quality of their produce and market access and thereby enhance their income. To enable the smallholder farmers, have access to inputs and other services, the government needs to systematically inject money to the financial institutions so that they can be able lend money to the farmers. Relaxing payback period from the beneficiary farmers and establishing agriculture banks/ insurance companies are also possible long-term mitigation measures.

Cooperatives and unions: Cooperatives and unions are critical instruments in implementing the objectives of the various development programs and strategies such as the rural development strategy, poverty reduction programs, and food security programs. Movement restrictions between cities and rural areas due to the pandemic may negatively affect their effectiveness. Such restriction could also hamper activities such as generation of input demand data. On the other hand, cooperatives (whether primary or multipurpose) and unions, in Ethiopia have much experience in activities such as seed production and marketing. It is feared that they may be overburdened (in terms of finance, human resource etc.) due to the COVID-19 pandemic. Interventions such as increasing the number of access points for input distribution and collaborating with DAs for better data exchange are some suggested mitigation measures to be implemented so as to enhance their capacity to be able to effectively serve the farmers.

NGOs: NGOs help farming community by providing inputs and technical support. The COVID-19 pandemic restricts movement of technical staff of NGOs, which negatively affects crop and livestock production and productivity. The pandemic could cause budget cut and restricts of movement of staff of NGOs, which negatively affects implementation of the planned activities. Therefore, re-planning of NGO operations, as per COVID-19 prevention guidelines, are required. Where possible, virtual communication of NGO staffs can be implemented to run the activities during their limited movement due to the pandemic. Since there could be duplication of activities by many NGOs, harmonization of their tasks will make effective resource mobilization at this time of scarcity. On the other hand, where NGOs fail to achieve what is expected of them due to this pandemic, government intervention is required to sustain these agricultural development activities. For instance, resource mobilization from other sources can be a possible mitigation approach.

Grassroots community groups: In traditional and local institutions (TLIs) such as Debo, people mobilize labor resource to overcome seasonal labor peaks. In Idir, members organize themselves to provide social and economic insurance in the events of death, accident, and damage to property. The current pandemic could weaken social bonds; disrupt a collaborative work of the traditional and local institutions (Debo, Wonfel, Idir, etc.). Therefore, concerned government bodies including local administrators, health extension workers (HEWs) and development agents (DAs) need to provide effective awareness creation to strengthen these traditional and local institutions while taking extra care to prevent potential COVID-19 spread. Rural communities with labor intensive activities are advised to focus on family labor by mainly utilizing the opportunity of school closure so that students can participate in agricultural activities of their family. Research: Research activities in Ethiopia could be disrupted as COVID-19 continues to spread. Resource could also be diverted from agricultural research to COVID-19 prevention. Nevertheless, researchers in the Ethiopian research system can contribute through making their latest research findings and analysis on COVID-19 available to support authorities and the public in making informed decisions during the current crisis (CGIAR, 2020). Researchers are expected to prepare rapid response evidence on impact of the pandemic on agriculture. Recognizing relevance of agriculture in achieving food and nutrition security, agricultural and food research activities should not be disrupted and there must also be proper budgeting for running the designed problem-solving research activities sustainably. 


\title{
Impacts COVID-19 pandemic Diseases on Ethiopian Agriculture, Food Systems, Industries, and Mitigation and Adaptation Strategy
}

\author{
Available at https://jscer.org
}

Choularton and Mallory (2020) have pointed out the following four major focus areas, among others, that the research and development community can start to take now: (i) increasing assessments of the effects of COVID-19 on agriculture and food systems. Just as increased testing for COVID-19 is critical for public health, so too is measuring its impact on agriculture and food systems, (ii) Supporting farmers to continue producing and marketing food. The research system can help farmers adopt labor-saving practices that compensate for reduced labor availability, for example, by sick family members, limitations on collective labor, and restrictions on the movement of people to producers' fields, (iii) Accelerating the deployment of relevant agricultural technologies and digital agriculture solutions. Agricultural technologies, especially digital agriculture solutions, offer a range of important opportunities to address the impacts of COVID-19 on agricultural production, labor availability, input supply, and logistics, and (iv) Assessing the impact of COVID-19 on agriculture-based livelihoods and food security using a gender lens. Approaches to address COVID-19 that carefully consider the gender dimensions of food security, labor, health, and vulnerability are essential.

\section{f. Effects on local administration}

As a short-term effect, the COVID-19 pandemic has negative effects on local administration decision making. During this pandemic period loose linkage is being observed among the various government bodies, for example between zonal and district administers, and among relevant stakeholders. Moreover, more emphasis is being given to COVID-19 control than food security (i.e., resource diversion). Planting period will start in the coming months for the main agricultural season while the COVID-19 epidemic is forcing government to cut agricultural expenses and to prioritize health related expenditures. Consequently, in the long-term, this pandemic will reduce agricultural production due mainly to less attention and resource given to agriculture. The probable short-term solution for the loose linkage among various government bodies is strengthening the linkage; define clear task and decision-making role of each actor. It is also good to enhance communication using existing IT (e.g., Woreda Net). As long-term solutions allocate budget and give due attention timely and effectively engage relevant government bodies in facilitating agricultural activities.

\section{g. Effect on desert locust control}

The current COVID-19 pandemic occurred while desert locust swarm is hitting East African countries including Ethiopia. The desert locusts are currently active in Ethiopia because of cross-border movements of immature swarms along the borders of Kenya and Somalia (FAO, 2020). Unless properly controlled, the locust invasion will cause large-scale crop, pasture, and forest cover loss, especially for pastoralists and households relying on short rains (February-May) for crop production in the country.
According to the Ethiopian Ministry of Agriculture (MoA) media briefing, 3.6 million quintals of grain was lost due to locust infestation. Restriction of movement as a prevention of COVID-19 may distract the effort of desert locust control and result in devastation of crops, pasture and forest cover loss worsening food and feed insecurity. Therefore, restriction of movement should be relaxed or totally lifted for the campaigns of desert locust control and there should be coordinated effort among federal and regional governments, community and development institutions such as FAO. Furthermore, the Ethiopian government should scale up survey and control measures by closely monitoring the desert locust situation, providing forecasts, early warning, regular updates and alerts through the global Desert Locust Information Service (DLIS) of FAO and scale up the areal and ground control operations. On the other hand, though it may not be culturally commendable to the Ethiopian population, locusts are studied to be rich in proteins, fatty acids and minerals that boost immunity, fight cancer and prevent inflammation of body organs if creatively incorporated into food and feed products (Clarkson et al. 2018).

\section{f. Restriction of pastoral movement}

Pastoralists represent 12 percent of the 100 million Ethiopian populations (FES, 2017). In addition to limited access to schools, hospitals or political decision-making processes, pastoralists are suffering because of recent developments in climate change and ongoing insecurity in the border regions. Pastoral and agro-pastoral communities around the world are building on centuries-old coping strategies and adopting complementary means of livelihood. Restriction of pastoral movement is expected to have more impacts on pastoral community as it exacerbates the already existing feed and water shortage in the area. Pastoralists come together for efficient utilization of the deep well water. They manually carry water from the deep well to the surface in a series of labor intensive system and provide their animals. The low infrastructure, frequent climate change and conflict in pastoral areas combined with the current expansion of locust outbreak in their localities need a special attention. As a short/term strategy, pastoralists should be provided feed and food stock (safety nets), advised to focus on small ruminants than large animals, and given awareness against the pandemic using the community structure by the combined effort of health extension workers and development agents. In the long-term, selecting drought tolerant varieties of plants for feeds, developing water wells and establishing feed banks could be alternative strategies. The pastoral community in Ethiopia also suffers from lack of market access for livestock/products and the illegal smuggling of live animals to the neighboring countries that affect the local market price. Therefore, establishing market linkage for their products to the local market as well as diversifying export of their animals and animal products can be suggested as long-term strategies. 


\title{
Impacts COVID-19 pandemic Diseases on Ethiopian Agriculture, Food Systems, Industries, and Mitigation and Adaptation Strategy
}

\author{
Available at https://jscer.org
}

\section{B. Probable Impact of COVID-19 on Handling and Storage of Agricultural Products, Food Systems, Industries and Mitigation and Adaptation strategy}

Roughly one-third of all food produced in the world is lost or wasted (FAO, 2019). Non-optimized handling (drying, cooling, cleaning, sorting, transportation etc.) and storage during supply chain processes are responsible for high share of the postharvest losses (Yahia et al., 2019). The pandemic is expected to hamper the handling and storage operations and consequently the extent of postharvest losses could only get worse. One of the causes of postharvest losses of agricultural produce during the COVID-19 pandemic is a labor shortage for undertaking handling and storage operations. In the short-term, harvesting and handling activities are affected due to unavailability/ unaffordability of hired labor. For instance, the traditional labor sharing institutions in practice for centuries, such as Debo, Guza, and Wonfel are banned due to the social distancing principle of containing the pandemic. In normal years smallholder farmers solve labor shortages by participating in these labor sharing schemes. These labor shortages result in more products to be left unharvested. The labor shortage can be alleviated if local administrations mobilize local communities to help at farm level handling activities while taking extra care to prevent potential COVID-19 spread. Government and the private sector can also supply harvesting machinery or technologies. In the long-run, seasonal agricultural labor migration will face barriers. Ensuring safety and availability of labor force in the field, in the packinghouse, or the store needs to be given emphasis. When the news of travel restrictions emerged, people have started stockpiling food, sometimes more than what they need. This may lead to quality deterioration of the stored food (e.g., flour caking and insect infestation e.g. flour mites). The losses due to stockpiling could be minimized by encouraging people to buy only amounts they need and guaranteeing the availability and accessibility of food during the peak periods of the pandemic. In the longrun, consumers should be encouraged to use improved postharvest technologies (e.g., hermetic bags for grain products).

When perishables (fruits, vegetables and flowers) are stored under improper storage conditions, a significant loss can be recorded. Temperature is the most critical factor influencing storability of perishables and absence of lowtemperature storage facilities leads to high losses. To solve this in the short-run, the government can rent cold rooms from commercial flower farms to store fruits and vegetables, which lead to storage life extension thereby ensuring continuous supply, stabilizing market price and promoting the health of citizens. Additionally, access to low-cost handling and storage technologies (e.g., evaporative coolers, crates) can be improved. In the long-run, the country needs to work aggressively to have cold storage rooms for perishables and establish efficient postharvest handling and storage systems with improving temperature and ethylene management. It is also good to encourage private investors to open more vendors and malls in main towns so that there will be more market for the perishables. Even if grains are naturally less perishable than fruits and vegetables, significant loss can be encountered due to improper storage technologies. These losses could be of qualitative (e.g., aflatoxin development) and quantitative (e.g., damage by weevil) in nature. In the coming few months, the government could optimize the use of public and private storage facilities that could be used for emergency food stockpiling. It can also set up and operate temporary warehouses (distribution centers) to store, and distribute the food applying physical distancing measures. Food stocks received earliest should be delivered first, the principle is known as FIFO (first in, first out). Similarly, cooperatives, unions and development partners can improve access to handling and storage technologies (e.g., storage bags, metal silos). In the long-run, the government may enhance the accumulation of food reserves and support construction of community or large warehouses.

Once the COVID-19 has been declared a pandemic, a sudden drop of consumer demand is noticed at the destination market; for some products, orders have been cancelled (e.g., flowers for mothers' day, poultry products, milk etc.). The demand for Ethiopian flower export drops by 70 percent (Addis Fortune, 2020). These cancellations have made farms to downsize or halt entirely handling, and storage practices and some farms have disposed of harvested flowers and milk as a waste. The food loss farms are encountering will have a financial consequence where later on they may not have sufficient money to run the farms. Consequently, farms face significant lay-off of workers which means no work force for grading, packing, storage and shipping of the produce. A high rate of unemployment could have social, political and economic implications. Local marketing of food products is an alternative option and farms may give a paid leave of absence to their employees with financial support from the government. Milk collection to some processing centers will stop or minimized due to closure of cafés and restaurants, and this will lead to dumping milk with high production cost on smallholder dairy producers. A short-term financial incentive mechanism for smallholder farmers and processors as well as long-term ultra-high temperature (UHT) processing of milk for longer storage at bigger cities are among the important mitigation methods. Currently, local transport is somehow restricted because people are encouraged to stay at home. As travel is discouraged or hampered, commercially matured or harvested perishable products are more likely to be lost. In such instances, it is better to encourage farming households to sell/eat more locally instead of sending the product to the market (Haddad et al., 2020). Gradually lifting bans on local movement and adopting the 'green channel' model for transport of perishables may also work.

Food safety concerns on fruits and vegetables increase since these produces could be touched by hand at the different stages of handling, which may lead to cross-

Page 85 


\title{
Impacts COVID-19 pandemic Diseases on Ethiopian Agriculture, Food Systems, Industries, and Mitigation and Adaptation Strategy
}

\author{
Available at https://jscer.org
}

contamination and spread of the virus. Education should be given to the public about the health benefits of increased hygiene, especially during handling of food products, and safe food. We need to also work on improving microbial management of food in handling and storage. In the longrun, investment towards shops/malls with food safety standards shall be encouraged. Food safety concerns may also increase on meat products due to claims of the zoonotic nature of COVID-19. In the short-run, awareness creation to consumers that there is no established evidence whether consumption of animal source food is associated with infection by COVID-19. Additionally, implementation and control of national food safety standards are necessary. In the long-run, more research and policy action on zoonotic diseases is required, especially for "wet" markets, and more generally on food safety.

\section{Probable Impact of COVID-19 on Processing and Packaging of Agricultural Products, Food Systems, Industries and Mitigation and Adaptation Measures}

Ethiopia is working strongly to explore the untapped agro-processing industries potential to boost its economy. Food and beverage processing industries are dominating the agro-processing industry in Ethiopia. Meat, fish, milk and dairy products, edible oil, fruits and vegetables, starch and starch products, pasta products, flour milling industries and different type of beverage products are the major products produced in the country. The sector has high potential to supply food to the local market, generate hard currency and create employment opportunities. In addition, it minimizes postharvest losses caused due to lack of sufficient storage places, and to produce shelf stable food products, diversify diet options and facilitate distribution and marketing system. It also sustains consistent market for producers through supply of raw materials and other inputs throughout the year. The sub sector helps to transform the country's economy from agriculture based to a light or medium industry-based economy. However, the current global pandemic is a treat to transform the sub sector as planned through hindering the normal practice and activities. Possible negative and positive impacts of the pandemic on food processing and packaging industries are briefly discussed below.

\section{a. Impact on dairy and fish industry}

According to Ethiopia Country Commercial Guide (2020), in the last 15 years, the volume of milk production has tripled, and the government aims to double its production by 2020. An increase in production is a good opportunity for expansion of dairy processing industries to be able to supply nutritious dairy products to the public. However, due to the occurrence of COVID-19, the local dairy demand and consumption has critically declined. This is mainly because of perception not to consume raw and chilled animal products with the assumption that such foods are the main routes for the transmission of the virus. As a result, consumers in major market destinations have either reduced the amount they buy or completely avoided consumption of raw fish, meat and chilled dairy products. This negatively affects the livelihood of producers, processors and value chain actors involved in the businesses. Restriction of movement, social distancing and closure of restaurants further limits the demand for milk and fish products.

The impact of the pandemic is overlapped with declined consumer demand for milk and fish products associated with the main fasting season of the Ethiopian Coptic Orthodox Church. Believers are restricted from consumption of animal-based products (meat, milk and egg-based products) between March 1 to April 25, 2020. According to personal communication (Ethiopian Milk Processors Association), in previous years (before the occurrence of the disease) there has been no such a case, except slight reduction of demand for milk and milk-based products during the fasting period. The current reduction of demand for milk and fish, associated with the pandemic, significantly affects the interest of processing industries in that collection of milk from collection centers could as well be reduced, which critically affects the suppliers than processors.

The high perishable nature (short shelf life) of milk and fish products means, the effect of the disease is more on producers than processors, as well other actors along the value chain. Based on guidelines of FAO and WHO (2020), there is no evidence as to whether food or food packaging are associated with the transmission of the disease and that no food recalls are anticipated if a person who works in a food or beverage production facility is diagnosed. Reduced production capacity of the fish and dairy industries could significantly hamper long-term growth of the sector due to high labor cost, especially if the work force is to be maintained for long period. This ultimately could lead to cessation of production and collapse of the industry (Figure 2) which can be manifested in terms of layoff of labor force, which in turn could aggravate food and nutrition insecurity, and depression of the country's economy at large.

The short-term mitigation strategy can accommodate the following points. (i) According to recommendation set by Chinese Centre for Disease Control and Prevention (CDC), Chinese Medical Doctors Association, government and NGOs, milk and other dairy products are an excellent source of high quality protein, vitamin B2, vitamin A, calcium and other nutrients essential for the human body to boost the immune system to fight the virus (Anonymous, 2020). Furthermore, coronaviruses cannot multiply in food; they need an animal or human host to multiply (FAO and WHO, 2020). Therefore, the government of Ethiopia should make a massive public awareness creation to show fish and dairy products are safe to consume after proper heat treatment or pasteurization, as these food products are importance to boost public immune system to control the disease. (ii) Food industries need to include good hygiene practices, cleaning and sanitation, zoning of processing areas, supplier control, storage, distribution and transport, personnel hygiene and fitness to work all the basic conditions and activities 


\title{
Impacts COVID-19 pandemic Diseases on Ethiopian Agriculture, Food Systems, Industries, and Mitigation and Adaptation Strategy
}

\author{
Available at https://jscer.org
}

necessary to maintain a hygienic food processing environment. (iii) One of the control mechanisms of the spread of the virus is avoiding public gathering, which leads to unprecedented contraction of hotels, restaurants and coffee houses. Therefore, the dairy industries and their distribution system need to switch the supply efforts from food service areas to retail channel or home to home delivery in large market potential areas, like condominiums and apartment buildings. A door-to-door milk delivery from processing industries through the existing distribution channels better to be accomplished along with awareness creation activities to restore back the trust and confidence of consumer. Local government authorities and experts in agricultural office should encourage producers to convert excess milks to other relatively better shelf life dairy products (e.g. local butter or butter cream). (iv) The government needs to establish subsidy mechanisms to support both producers and processors so as to sustain the dairy industry. Immediate technical advises and facility support need to be offered to producers to convert raw milks or fresh fish to other relatively shelf stable products like production of butter and cheese from milk and dried fish meat.

Extended lack of demand for dairy products and fresh fish ultimately enhances the production costs with less or no income to cover feed and other operation costs. This will lead to hampering or completely halting the dairy and fish value chains and eventually leads to the collapse of the industry, worsen unemployment due to labor layoff, enhance economic crises, and aggravate food and nutrition insecurity gaps. In the long-run, to sustain the dairy and fish supply, the following points could be forwarded as a recommendation: (i) A mechanism need to be developed to consult professional societies and relevant civil associations before media advertisement or advise of food products in order to avoid spillover effect from one advertisement to the other. For instance, a professional advice and advertisement from ministry of health may overlook the short- or longterm impact on agriculture sector. (ii) Dairy processing industries could consider the production of shelf stable milks (UHT milks) to cope up with the current market gap where excess milk is supplied to the industry and temporary decline in demand of milk occurred. (iii) Market and product diversification can be considered as an option. The government needs to establish incentive and subsidy mechanisms to the dairy industry in terms of share of production cost, tax exemption, loan payment extension, interest rate cancellation etc.

\section{b. Impact on meat exporting abattoirs}

Despite shortage of cattle for abattoirs due to restriction of movements in major cattle markets (pastoral, agropastoral communities), the volume of fresh meat exported to different Middle East countries is increasing as compared to the previous years. Middle East countries as net importer of food items import and stock enough food to meet the demand of their nation at least for six months. The pandemic has resulted in decline of global supply/export of meat and meat products to the Middle East countries but has opened good opportunity to abattoirs in Ethiopia. Particularly the volume of meat exported to UAE and Saudi Arabia is increasing during early the time of the disease (March and April). This can be an opportunity to narrow down the hard currency gap created due to lack of export of flower to Europe.

It is better to forward the following recommendations to enhance the available opportunity to boost export of meat to Middle East countries. (i) Develop a mechanism to increase the supply of live animals to modern abattoirs so as to enhance the volume of meat to be exported (i.e., to meet increasing demand in the Middle East). During such pandemic and natural disaster period, food is always on the top list of consumers as compared to other non-food items. This is an opportunity to establish and strengthen good market links with net importer countries. Therefore, creating conducive system for supply of live animals to modern abattoirs could sustain production and supply of the meat. Therefore, relaxing restriction of movement, including in pastoral community areas, and as well creating conducive legal issues associated with supply of live animals needs due consideration, especially at this time wherein the countryimposed state of emergency. (ii) Easing or lifting of existing production and export barriers for the abattoirs could enhance the supply of products and generation of hard currency for the country. Supporting the handling and transportation sector could play important role to enhancing the efficiency and capacity of the exporter. (iii) Additional market destination needs to be sought to diversify market outlets.

In the long-term, the government policy and incentive direction need to incline (i) to support food-processing sector as compared to non-food processing industries. (ii) Market diversification also needs consideration to enhance the supply of meat and meat related products to diverse markets than only limited to Middle East countries. (iii) Financial and technical support from the government, longterm tax exemption and provision of loan, exploring joint venture opportunities deserve due attention.

\section{c. Impact on industries producing shelf stable products}

Shelf stable products that comprise, cereal-processing industries like flour millers, oil seeds processors, bakery industry, pasta and macaroni producers, and coffee processing warehouses. These agro-processors are less affected by current pandemic as compared to those produce perishable products. In general, demand of processed food from such food industries is rising with change on consumption behavior of the nation, price advantages, convenience and other issues. However, at this pandemic moment, the demand and price of these products is increasing alarmingly with the intention of stockpiling of extra foods by panic buyers. In the short-term, such industries can sustain production and supply levels of their

Page 87 


\title{
Impacts COVID-19 pandemic Diseases on Ethiopian Agriculture, Food Systems, Industries, and Mitigation and Adaptation Strategy
}

\author{
Available at https://jscer.org
}

processed products. However, with an increase in disease pressure, in the long-term, the industries could experience shortage of supply of packaging and raw materials.

From coffee processing point of view, the country exported 3.98 million $60-\mathrm{kg}$ bags of coffee in $2017 / 18$ generating $\$ 897$ million revenue and is expanding the production to reach $\$ 2$ billion in sales by $2019 / 2020$ (Ethiopia Country Commercial Guide, 2020). In recent months (January to April 2020, before early impact of COVID-19) the country has been processing and exporting coffee as planned because of pre-signed contract agreement with buyers. However, the future trend may change because of decline of demand on international markets due to closure of coffee retail shops like Starbucks, restaurants and cafés. In Ethiopia, Coffee processing and grading companies are labor intensive, engaging large number of women per unit area, which probably could be challenging to implementing social distancing and avoiding public gathering as preventive measures of a potential virus spread. This necessitates to creating safe working condition for the workers to accomplish their regular activities. If this condition could not be met, the volume of coffee supplied to international market could be hampered due to pressure of the disease at processing sites. In addition to this, the international market is also expected to decline due to closure of coffee stores, restaurants and cafés. For instance, according to Starbucks CEOs (Kevin and Partick, 2020), during month of February 2020, in China market the Starbucks comparable sale was 78 percent down as compared to same month sale in 2019. Perhaps more of such decline is expected at this time and even in near future in USA and other European countries. However, close to 90 percent of the Starbucks stores in China are back to normal work and the same trend hopefully could continue on other COVID-19 affected potential markets as well. However, persistent market search and strong link with existing customers are necessary to maintain at least the planned export volume of coffee. Therefore, the anticipated gain in foreign currency may not meet for the fiscal year if there is a loop to miss potential customers. This will also have a spill over effect for the sector in the long-term to loss potential customers and position of the country in global coffee market.

The following points can be considered as short-term strategies to lessen the impact of the pandemic on shelf stable processed agricultural products. (i) The current less pressure of the pandemic in the country is an opportunity to enhance the production capacity of the industries to compensate decline in supply of the products at time of the pandemic high pressure. (ii) The government together with processing industries needs to ensure the supply of packaging and raw materials through sustaining the current supply chain either from local markets or through import. (iii) Financial support and other incentives from the government are important to maintain and sustain full production capacity of the industries. (iv) The industries should develop a strategy to maintain their production even during high pressure of the disease in collaboration with the government. (v) Implementation of laws, rules and regulations as well as guidelines in line with the current state of emergency needs to be drafted so as to support the smooth production and flow of food and packaging materials, while implementing preventive measures of the disease. For example, the federal government could exempt food processors from rules that prevent the gathering of more people until the coronavirus emergency is over. It is necessary to keep food processors or manufacturers as part of essential services to ensure food and nutrition security during and even after the pandemic. This means a critical consideration upon implementation of the guidelines or rules and regulations of the current state of emergency is important to be well aligned with food processing industries.

In the long-run, the government could consider the following points to overcome a potential severe impact of the disease in food processing subsector. (i) The current scenario (crisis period) showed that, food industries for shelf stable products being less affected as compared to perishable food industries. This is mainly because of high demand for shelf stable products by urban consumers to stock foods for extended period to ensure household food security. The government needs to promote the establishment of large number of such types of food industries throughout the country. Such types of food industries are more resilient to such type of natural or artificial disasters and meet public food demand as compared to perishable foods. This ought to be the same for packaging industries to sustain constant supply of packaging materials for the industries. (ii) A sustainable supply of raw materials for the industries is necessary to maintain the work force and supply of food for long period. Experiences indicate that in Ethiopia very often medium and large-scale food processing industries suffer from lack of raw materials and inputs to perform in full capacity. Restriction of movement and social distancing might further disrupt the normal supply chain of raw materials and other inputs like packaging materials. This could lead to scaling down or cessation of production and in the long-run it could result in labor force layoff and shortage of the products. This will eventually push the industries out of the system unless and otherwise copping strategies are brought into effect ahead of time. Therefore, the supply side needs to work efficiently to maintain constant supply of raw materials and other inputs for the industries. (iii) Long-term financial support from the government side, product and market diversification, import substitution for certain ingredients and efficient supply chain system are few of the points that need to be addressed by the government to transform the current small and medium industries to large scale ones. (iv) There is a need to seek sufficient fund from different international sources to support the food processing industries. The food industry should get priority and robust support from the government and other lending agencies / donors as compared to industries involved in non-food items. An emergency rescue package that would enable poorly performing industries to 
provide cash grants or bail out of vulnerable small businesses is also important.

In addition to mitigation strategies indicated above, the following points are forwarded as a general remark (short and long-term) for all food processing industries to cope up with a probable impact of COVID-19 and other similar disasters in the long-term.

i. As a short-term strategy, existing food processing industries need to follow and apply "COVID-19 and food safety: guidance for food businesses" of Food and Agriculture Organization and World Health Organization of the United Nations (FAO and WHO, 2020).

ii. Recent research evaluated the survival of the COVID-19 virus on different surfaces and reported that the virus can remain viable for up to 72 hours on plastic and stainless steel, up to four hours on copper, and up to 24 hours on cardboard (van Doremalen et al., 2020). To avoid the transmission of the virus the products can be hold for a maximum of 72 hours before distributing them to avoid a possible cross contamination during distribution if there is a suspect of positive case in food processing industries or cross contamination from Personal Protective Equipment (PPE). Surface decontamination of the packaging materials could also be an alternative option for immediate distribution of the packed foods. A continuous training on personal hygiene, possible routes of cross contamination, symptoms and identification of the disease and care during handling, transportation and marketing of the products should be given to the work force in the supply chain of the product.

iii. In the context of rising demand for processed food products, medium- and large-scale food processing companies in Ethiopia often reflect lack of raw material inputs as a main constraint hindering their ability to work at full capacity. This is a critical problem to avoid food selfinsufficiency even in good time. Therefore, the supply side needs critical consideration to produce, store and deliver enough raw materials for all food processing industries.

iv. Food industry should have Food Safety Management Systems (FSMS) based on the Hazard Analysis and Critical Control Point (HACCP) principles in place to manage food safety risks and prevent food contamination. Implementing these food safety measures in all food industries during good days will insure production of safe foods at time of disaster.

Ethiopia is establishing Integrated Agro- Industrial Parks (IAIPs) with potential investment of USD 1.5 billion for estimated 400 business opportunities to employee 400,000 jobs (Ethiopia Country Commercial Guide, 2020). As a long-term intervention, the current efforts of the government to establish IAIPS in 17 selected target areas need be hasten to transform the current low contribution of agro processing industries to the maximum potential of the country.

\section{Impact of COVID-19 on Distribution and Marketing of Agricultural Products, Food Systems, Industries and Mitigation and Adaptation strategy}

Due to the COVID-19 pandemic outbreak, food distribution and marketing of the country would be hard hit. Given that the food distribution and marketing system is not well developed due to underdevelopment of infrastructure and shortage of skilled human power, the pandemic will have adverse effects on food supply chains - supply side as well as the demand side. On the supply side, the most important short-term effect is food scarcity in the urban and peri-urban areas due to reasons such as movement restrictions, increased frustration or withdrawal of value chain actors (producers, rural/urban food collectors, wholesalers, retailers or consumers) (Reardon et al., 2020). The food supply chain in Ethiopia is labor intensive. In essence, producers transport food crops and animal products from rural areas to nearby urban settings using their family labor, draught animals, and carts. As a result, they can only transport a small amount of food commodities, which requires a large number of people or draft animals to come to the marketplace to transport a significant amount. On the other hand, the restrictions on movement make it difficult for rural and urban collectors to move from place to place or market to market freely. Furthermore, the restrictions on movement, together with the frustration of value chain actors, not to be infected by the virus, could reduce the amount of food commodities arriving at urban areas leading to temporary food shortage.

The possible solutions to increase food availability in the urban areas in response to the above challenges include, enhancing the capacity of producers cooperatives, by providing them with clear orientation on COVID-19 prevention mechanisms to collect food from producers by establishing handwashing locations, using disinfectants, and communicating time table to the suppliers, while keeping also proper physical distance from one another. They can systematically schedule in such a way that farmers from the same village can supply on the same date to minimize congestion of food suppliers at the cooperatives' sites. Besides, local administrators can arrange many foodcollection points in the villages where cooperatives can collect food commodities from suppliers. Given that most of these cooperatives are closer to all-weather roads, and that they can have better access to a truck, they can transport food to urban areas. It is also possible that consumer cooperatives in urban areas can purchase food from producer cooperatives, transport to urban areas and distribute to consumers. This will have multiple benefits: first, it reduces the spread of the virus if carefully managed - only a few people operate at producer cooperative level; altering the date traders come to reduce congestion at the cooperative site; arranging places for handwashing; shipping using large truck where only a few people need to come. The same can be used at consumption end - only a few people operate at consumer cooperatives based on schedules for consumers. Second, it increases employment Page 89 


\title{
Impacts COVID-19 pandemic Diseases on Ethiopian Agriculture, Food Systems, Industries, and Mitigation and Adaptation Strategy
}

\author{
Available at https://jscer.org
}

opportunities, especially if the unemployed youth can support in handling crops at consumer cooperatives. Third, it reduces the income loss of farmers that might arise due to difficulty to move commodity to towns and cities. Evidence shows that farmers, especially vegetable producers, have lost income due to less movement and lower prices (Tamru et al., 2020). Fourth, consumer cooperatives can transport processed products such as oil from urban to rural areas, which can be distributed to rural consumers through producer cooperatives. To capacitate the efficient operation of both producer and consumer cooperatives, financial support by the government and financial institutions needs to be prioritized.

Another short-term supply-side impact is related to reducing overcrowd of buyers and sellers in rural and urban market areas. This also limits the availability of and access to food items and other commodities among buyers and sellers. The possible solution for this is that local administrators can open up new marketplaces, alter market dates, allow people to transact by keeping their social distance and applying all the possible prevention mechanisms. Such solutions are supported by International Food Policy Research Institute (IFPRI) (Resnick, 2020). Opening up additional marketplaces and altering market dates give additional room to disinfect the marketplaces on the off days. Other options that can enhance food availability might include reducing the export of staple food items, importing food in bulk and requesting emergency food aid. Literature shows that under normal situation, 7-14 million people in the country are estimated to be food insecure (OCHA, 2020), which needs emergency food aid. Adding the effect of COVID-19, which can reach up to 10 million people, would increase the need for food donation from international donors. In the long-run, if the spread continues for the coming production season, food shortage will continue to be a challenge. As part of the preparedness, relaxing travel ban as the awareness of people on the virus will increase and reorienting the marketing and food distribution system - the need for the emergence of big companies and supermarkets in vending food; and specialized food transporters could help. Further strengthening the capacity of producer and consumer cooperatives to enhance their bargaining power and thereby stabilizing the prices are important measures that can be put in place to transform the food supply chain from traditional and transitional to modern supply chains. Furthermore, it is important to encourage small and micro enterprises to emerge and distribute food, to look for alternative genuine and reliable individual distributors and entrepreneurs.

The other important short-run effect is information asymmetry among the suppliers. Suppliers might hoard crops in their store, fearing for long-term effects of the pandemic, if they do not have clear information. And some countries might induce export ban even though they are surplus producers. E.g., Uzbekistan and Vietnam have already induced export ban on rice while they are suppliers of a large amount of rice to the global market (e.g., 16 percent of the global rice comes from Vietnam) (Glauber et al., 2020). This negatively affects the food import of the country. The short-term solution is ensuring transparent, stable and reliable source of information regarding food supply and negotiating with exporting countries, in collaboration with all concerned stakeholders, to increase food supply to the world market. Literature shows that there is no immediate food shortage in the global market for the coming 10 to 13 months (Glauber et al., 2020); hence, opening up markets will be an advantage. At the same time, the country can introduce the Chinese "green chain" model where an import is opened up for medical and food commodities, keeping all transactions to be audited after the crisis. In the long-run, the government can open up trades by reducing import tariffs to reduce the negative effects of the import ban on food availability.

Most of the above reasons combined with adulterations by unethical traders, and rising producers and traders' expectations will lead to food price hikes in the short-term and absence of some food crops from the market in the longrun and leaving the poor behind from getting access to food. Literature shows food price increase in some African countries following the pandemic outbreak (Resnick, 2020). Capacitating urban micro-enterprises or consumer cooperatives can manage such effects. Kebele level consumer cooperatives should be capacitated to store and distribute foods. Access to credit /financial resources for consumption smoothening would also help. Local administrators should also control illegal traders (wholesalers and retailers) from adulteration and artificial price increase. It is also important to take this opportunity and upgrade sanitation in wholesale and retailers' markets, maintaining its long-term effects even after COVID-19. Better preparedness is also needed; awareness rising among the producers to produce more productive food crops (e.g., maize vs teff) and among consumers to shift their consumption to the more productive crops.

The demand side effects are also important. As constraints on logistic continue, many value chain actors withdraw from food trade, unemployment and income loss increases, which can even lead to crisis and unrest in the towns and cities due to inability to get access to food (Bellemare, 2015 cited in Reardon, 2020). Literature shows that due to lockdown, China has lost over $\$ 100$ billion from rural migrant labor (Rozelle et al., 2020). Local administrators can give safety net (cash for work) for those who are unemployed and engage them in emergency food distribution and give cash vouchers for disabled people. In the long-run, it is pertinent to work with financial institutions, enhance credit services, and lend more money to micro and small enterprises so that they can employ more people. Also, it is important to take this opportunity to legalize the informal food traders and support them. This will have a positive impact on the economy of the country in the long-run. Food price hikes can also be induced from the demand side due to bulk demand by consumers consumers' stockpiling, which emanates from rising

Page 90 
consumer expectations about the future. This probably will leave many poor people behind getting access to food; enhance hunger and food insecurity in the long-run. The immediate solution is creating and raising awareness by providing reliable information about food availability. Also monitoring and controlling food prices is of paramount importance. In the long-run, enhancing food reserve and redistribution to the community, upgrading consumers' awareness about food quality and safety, upgrading their sanitation in food purchase - especially the perishable ones - is very important. Another important impact is related to confusion among consumers about some food items. Some evidence shows [though not confirmed] that COVID-19 originate from Chinese wet market links it to the consumption of raw products. This has brought about frustration on consuming some plant and animal products that are rich in vitamins and minerals. Though consuming raw is not recommended at all for some products, consumers must get the right information and decide the mode of consumption for such products without destroying its nutritional value. Avoiding consumption of raw meat, especially for Ethiopians after Easter fasting period is a caution; consumers should consider not only avoiding possible contamination with COVID-19 but also due to potential risk of tapeworm.

There is a reduction in the number of customers in the restaurants, cafés and small and micro-enterprises such as roadside cultural coffee markets. This, in the long-run, can even result in the withdrawal of some of the restaurants and cafés from the economy. To encourage such businesses to keep operating, it would be helpful if the local tax and revenue authorities give them tax exemptions. In the medium and long-run, it is helpful for them to change their mode of delivery - delivering food at the door of their customers.

Finally, the country loses hard currency as there will be low demand in the international market for high-value crops such as flowers, fruits and vegetables that Ethiopia exports. For instance, according to the ministry of agriculture flower export has fallen by 70 percent due to the COVID-19 in the last three months. The country will face a further shortage of hard currency. Reducing taxes, opening up trades, market segmentation and diversification are (searching for new markets) especially in countries where COVID-19 is not highly prevalent and where it is diminishing can help the country to get hard currency.

Moreover, the export of coffee has received more demand from the global market as the consumption of coffee increases as people stay at home. The coffee authority also reports the highest revenue from the coffee export in the last couple of months. Therefore, the country can empower coffee cooperatives and exporters to increase foreign currency earnings from coffee export.

\section{E. Probable Impact of COVID-19 on Consumption of Agricultural Products, Food Systems, Industries and Mitigation and Adaptation strategy}

This section presents the probable impacts and potential mitigation strategies of COVID-19 pandemic on food consumption, including high-value food items (fruits and vegetables, animal products, sea food and fish products), food and nutrition security, food prices and purchasing power, and on service providers such as restaurants.

\section{a. Impact on consumption of fruits and vegetables, animal products, seafood and fish products}

As a result of COVID-19 related misinformation, the consumption of fruits and vegetables, animal products, seafood and fish products will be reduced in the short-term. The COVID-19 virus appears to have originated with animals, possibly pangolins and spread to humans, but there is no evidence that the virus has spread through the livestock sector or by consuming animal products. It is necessary to provide the public with a transparent, stable, and reliable source of information regarding national markets, food supply and the safe consumption of such food items. In the medium and long-term, the availability of these food items might decline in the market due to less supply as producers are hard hit from the loss of previous low prices. The government can ensure the continuous availability of such high-value food by making efforts at national and international levels.

\section{b. Impact on food and nutrition security}

There are high foods and nutrition insecurity of vulnerable communities in the East Africa region, including Ethiopia (FSNWG, 2020) due to climatic effects, economic challenges induced by high food prices, an outbreak of livestock pest and diseases, desert locust outbreak, regional conflicts, and population displacements. In particular, for the current agricultural seasons, the ongoing desert locust outbreak demands increased concerns about further food security deteriorations. On top of this, the current COVID19 crisis could significantly increase the food and nutrition insecurity of the vulnerable communities, both in the short, medium and long-term time frames bringing increased dependency on food aid. The government structure should make close monitoring in the most vulnerable areas, give emergency shelter and food assistance through donation and resource mobilization, strengthen social safety net mechanisms to maintain food and nutrition security of the poor and the most vulnerable. In the medium and long-term, the government needs to work on the rehabilitation of the displaced people, create more employment opportunities, and strengthen the small-and-medium-sized enterprises.

\section{c. Impact on food prices}

Government media briefs indicate that COVID-19 has significantly affected the prices of food items following

Page 91 


\title{
Impacts COVID-19 pandemic Diseases on Ethiopian Agriculture, Food Systems, Industries, and Mitigation and Adaptation Strategy
}

\author{
Available at https://jscer.org
}

panic buying; hoarding by traders, and disruptions along the food value chain (e.g., processing, transportation between rural and urban areas and regionally) could drive higher prices in certain areas, limiting food access for poorer households. This price hikes due to a shortage in the supply caused by movement restriction can be tackled in the shortterm by taking control measures to lessen shocks to the food supply chains. The control of wholesale and retail markets to minimize artificial price increases and the use of cooperatives and unions for doorstep supply of basic needs during the emergency/lockdown can also be among the necessary measures. In the medium and long-term, there will be less food availability due to lag in production seasons; hence, leading to a shortage in the supply and further price hikes. This needs measures to lessen shocks to the food supply chains, for instance, through injection from food reserve.

\section{d. Impact on purchasing power}

Consumers will have low purchasing power due to travel restrictions, layoff, low income and other crises resulted from COVID-19 (Kufuor and Beddington, 2020). The authors also indicated that during the economic crisis of 2007 to 2012, poorer consumers responded to price spikes by reducing purchases of nutritious foods while prioritizing the consumption of lower quality staple foods. Mobilization of food banks and efforts by charities and NGOs to deliver food can play critical roles to reduce the impact of this crisis. The organization and strengthening of daily laborers in the group under cash for work to vender food postCOVID-19 might also be essential to reduce the impact on the purchasing power.

\section{e. Impact on restaurants}

In the short-term, closure of restaurants in the steps to fight the COVID-19 crisis could affect readymade food availability. This mainly affects those people who are not cooking at home and entirely dependent on restaurants. The government should encourage restaurants to continue their service by ensuring the safety of food and food-system workers through local administrators and health workers. The Chinese "green channel" approach for innovative basic needs distributors at door front can also help as a mitigation strategy in this regard. The number of restaurants might decrease due to hard-hit during COVID-19 in the mediumand long-term impacts. It is vital to promote the safe preparation of food at home and change in lifestyle and consumption behavior. The government can take measures such as financial injection into the system for selected restaurant service providers.

\section{CONCLUSION}

Following the COVID-19 outbreak in China and spread to almost all countries in the world, governments and all concerned stakeholders are paying maximum attention on containing spread of the virus. Developing countries in general and Ethiopia in particular are implementing different policy measures including diverting large proportion of resources to the health sector, partial lockdowns, state of emergency, social distancing and avoiding crowds. Though the measures can help to reduce health crisis due to the pandemic, they could divert attention from agriculture sector and adversely affect the food and nutrition security of the country by disrupting food supply chains. The current assessment (experts' opinions and desk review) by the multi-disciplinary team of experts at Haramaya University highlights, in a comprehensive manner, the probable effects of COVID-19 and their respective adaptation and mitigation strategies on different functions and stages of food supply chains including production, handling and storage, processing and packaging, distribution and marketing, and consumption. At production level, the pandemic outbreak is expected to negatively affect crop and livestock production inputs, labor, psychological aspects of producers, agricultural extension support system, supporters/service providers, local administration, control of desert locust, and pastoral movement. At the level of handling and storage, it can result in labor shortage, loss due to stockpiling, improper storage technologies, and cancellation of orders, transport restrictions and food safety. Processing and packaging are affected through reduction or cessation of production, labor layoff, production and supply of less safe and poor-quality product, shortage of running capital, absence or shortage of key technical personnel, and psychological implication. At distribution and marketing level, it could result in scarcities of food in the urban due to movement restriction, withdrawal of value chain actors, slow down trading, import and export bans, food price hikes, reduced supply and demand for some food items due to information asymmetry and loss of hard currency. At the consumption level, the pandemic is expected to negatively affect the consumption (due to perceived misinformation) of some products such as fruits and vegetables, animal products, seafood and fish products; households' food and nutrition security, food prices and purchasing power, and restaurant services. Based on the experts' opinions and desk review by the multi-disciplinary team, the following shortterm and medium- and long-term adaptation and mitigation strategies have been forwarded. To minimize disruptions to farm input supply, ensuring availability and timely delivery of agricultural inputs with affordable prices should be prioritized in the next few months. Labor shortage can be reduced through careful movement of labor to areas of labor-intensive production. It is also important to encourage returnees from cities and towns, and students to work on family farms. In the long-term it is important to encourage technical innovations and contract farming to come up with labor saving technologies. Labor layoff from commercial farmers can be reduced through encouraging farms to operate safely and through government subsidy so that they can maintain their labor and linking them to markets through multilateral negotiation among the countries that purchase the farms' products. Agricultural extension support systems can focus on family extension in the short-term and IT based

Page 92 


\title{
Impacts COVID-19 pandemic Diseases on Ethiopian Agriculture, Food Systems, Industries, and Mitigation and Adaptation Strategy
}

\author{
Available at https://jscer.org
}

extension system in the long-term. Enhancing rural financial access, support of cooperatives and unions to farmers, NGOs, grass root organizations, and paying attention to agricultural research and development to come up with long-term solutions are crucial. Proper post-harvest management practices should be implemented to minimize quantitative and qualitative post-harvest food loss and waste through community mobilization, using combine harvester at potential areas, ensuring the safety of workers in the field, pack houses and store; improving postharvest technologies and ensuring food safety. At processing and packaging, ensuring the availability of raw materials and labor, subsidizing the companies to maintain their workers, giving them tax exemption, enhance better storage and distribution capacity, encourage product and market diversification, and putting in place quality control and monitoring are very important. Distribution and marketing should be strengthened through capacitating producers and consumer cooperatives; supporting value chain actors to function properly, opening new market places, controlling and monitoring prices, enhancing food availability through imports and probably reducing the export of staple food commodities and food aid, enhancing access to food by vulnerable community through creating cash for work schemes. Food utilization should be revitalized by providing transparent reliable and stable information on food safety, controlling prices, enabling cafés and restaurants to diversify their services with food and workers safety, and encouraging door to door food vending services.

\section{REFERENCES}

[1] Addis fortune. 2020. COVID-19 outbreak puts flower exports in danger. https://addisfortune.news/covid-19-outbreak-putsflower-exports-in-danger/nAccessed on April 10, 2020.

[2] Anonymuos.2020. Fight COVID-19 with dairy? China industry associations issue consumption guidelines to build immune resistance'.https://www.foodnavigatorasia.com/Article/2020/03/17/ Fight-COVID-19-with-dairy-China industry-associations-issueconsumption-guidelines-to-build-immune-resistance, Accessed APRIL 162020.

[3] Agricultural Transformation Agency (ATA). 2015. Annual Report - Transforming Agriculture in Ethiopia. http://www.ata.gov.et/download/annual-report-transformingagriculture-in-ethiopia/.

[4]CGIAR, 2020. CGIAR's Response to COVID-19. https://www.cgiar.org/news-events/all-news/our-response-tocovid-19.

[5] Choularton R. and Mallory M. 2020. Opinion: How to address the impact of COVID-19 on global food systems. https://www.devex.com/news/sponsored/opinion-how-to-addressthe-impact-of-covid-19-on-global-food-systems-96892.

[6] Claudia Clarkson, Miranda Mirosa, and John Birch. 2018. Potential of extracted Locusta migratoria protein fractions as valueadded ingredients. Insects. 9(1):20.

[7]https://www.researchgate.net/publication/323096919_Potential_ of_Extracted_Locusta_Migratoria_Protein_Fractions_as_ValueAdded_Ingredients,Danielsson, J., Macrae, R., Vayanos, D., \& Zigrand, J.-P. (2020, April 1). We shouldn't be comparing the coronavirus crisis to 2008 - this is why. Global Agenda. Ethiopia Country Commercial Guide. 2020.
[9] Food and Agriculture Organization of the United Nations (FAO). 2018. Ethiopia: Report on feed inventory and feed balance, 2018. Rome, Italy. 160 pages. Licence: CC BY-NC-SA 3.0 IGO

[10] FAO, 2019. Food Loss and Food Waste. http://www.fao.org/food-loss-and-food-waste/en/. Accessed April 20, 2020.

[11] FAO, 2020a. Addressing the impacts of COVID-19 in food crises. April-December 2020 FAO's component of the Global COVID-19 Humanitarian Response Plan.http://www.fao.org/emergencies/appeals/detail/en/c/1270012/ FAO. 2020b. Ethiopia - Desert Locust situation update. April 2020.

[12] https://www.fao.org/emergencies/resources/documents/resourc es-detail/en/c/1270162/FAO and WHO.2020. COVID-19 and food safety: guidance for food businesses, Interim guidance April 7, 2020 .

[13] Friedrich-Ebert-Stiftung (FES), 2017. Pastoralism in Ethiopia. Policy dialogue, Addis Ababa Ethiopia.

[14] FSNWG, 2020. COVID-19 food security and nutrition alert. Food security \& nutrition working group, OCHA. Available online: https://reliefweb.int/report/world/covid-19-food-securityand-nutrition-alert-30-march-2020.

[15] Glauber, J., Laborde, D., Martin, W. and Vos, R. 2020. COVID-19: Trade restrictions are worst possible response to safeguard food security. Available online: https://www.ifpri.org/blog/covid-19-trade-restrictions-are-worstpossible-response-safeguard-food-security (accessed on 09 April 2020).

[16] Haddad, L., Fanzo, J., Godfrey, S., Hawkes, C., Morris, S., \& Neufeld, L. (2020). The COVID-19 Crisis and Food Systems: addressing threats, creating opportunities. Gainhealth. https://www.gainhealth.org/media/news/covid-19-crisis-and-foodsystems-addressing-threats-creating-opportunities.

[17] HGT and LIFT, 2019. Improving the agricultural inputs market to work better for smallholder farmers in Ethiopia. A case study of Harvest General Trading (HGT) and their partnership with the UKAid-funded Land Investment for Transformation (LIFT) programme

[18] Kevin J. and Partick G.2020. Letter from Kevin Johanson and Partick Grismer.

[19] Kufuor, J. and Beddington, J. 2020. COVID-19, Food systems and nutrition: Statement from our co-chairs, IFPRI. Available online: https://www.glopan.org/covid-19-food-systems-andnutrition-statement-from-our-co-chairs/.

[20] Mahendra Dev S., 2020. Addressing COVID-19 impacts on agriculture, food security, and livelihoods in India, International Food Policy Research Institute (IFPRI).

[21] OCHA, 2020. Ethiopia: COVID-19 Humanitarian impact Situation Update No. 01. Available online: https://reliefweb.int/report/ethiopia/ethiopia-covid-19-

humanitarian-impact-situation-update-no-01-31-march-2020 (accessed on 08 April 2020).

[22] Reardon, T., Bellemare F.M. and Zilberman, D. 2020. How COVID-19 may disrupt food supply chains in developing countries. Available online: https://www.ifpri.org/blog/how-covid19-may-disrupt-food-supply-chains-developing-countries (accessed on 09 April 2020).

[23].Reperant, L. A., \& Osterhaus, A. D. 2017. AIDS, Avian flu, SARS, MERS, Ebola, Zika... what next? Vaccine, 35(35), 44704474.

[24] Resnick, D. 2020. COVID-19 lockdowns threaten Africa's vital informal urban food trade. Available online: https://www.ifpri.org/blog/covid-19-lockdowns-threaten-africasvital-informal-urban-food-trade (accessed on 09 April 2020). 
[25] Rozelle, S., Rahimi, H., Wang, H. and Dill, E. 2020. Lockdowns are protecting China's rural families from COVID-19, but the economic burden is heavy. Available online: https://www.ifpri.org/blog/lockdowns-are-protecting-chinas-ruralfamilies-covid-19-economic-burden-heavy (accessed on 09 April 2020).

[26] Tamru, S., Hirvonen, K. and Minten, B. 2020. The Coronavirus disease (COVID-19) crisis and food value chains in Ethiopia: Insights from vegetable value chains. Available online: http://essp.ifpri.info/2020/04/06/the-coronavirus-disease-covid-19crisis-and-food-value-chains-in-ethiopia-insights-from-vegetablevalue-chains/ (accessed on 08 April 2020).

[27] Tamiru S., Hirvonen K. and Minten B.2020. Impact of COVID-19 crises on vegetable value chains in Ethiopia. https://www.ifpri.org/blog/impacts-covid-19-crisis-vegetablevalue-chains-ethiopia (Accessed on April 14, 2020).

[28] Thome, K., Meade, B., Rosen, S., \& Beghin, J. C. 2016. Assessing Food Security in Ethiopia with USDA ERS's New Food Security Modelling Approach.

[29] van Doremalen N, Bushmaker T, Morris DH et al. Aerosol and Surface Stability of SARS-CoV-2 as Compared with SARSCoV-1. N Engl J Med. 2020 Mar 17. doi: 10.1056/NEJMc2004973 [30] Wegayehu Bogale and Mmatlou Kalaba, 2017.

[31] Rural Financial Services and Effects on Livestock Production in Ethiopia. International Conference on Livestock Finance and Value chain Royal Swazi Spa, Ezulwini, Swaziland, 21-23 February 2017WHO. 2020. Report of the WHO-China Joint Mission on Coronavirus Disease 2019 (COVID-19). 16-24 February 2020.

[32] World Bank, 2020a. Harnessing Continued Growth for Accelerated Poverty Reduction: Ethiopia poverty assessment.

[33] World Bank, 2020b. Assessing the economic impact of COVID-19 and policy responses in sub-Saharan Africa an analysis of issues shaping Africa's economic future. Africas Pulse volume 21 April 2020. 